\title{
Administration of anti-glucagon-like peptide-2 serum suppresses epithelial cell proliferation of the distal small intestine in weanling rats
}

\author{
Satoshi Ishizuka ${ }^{1}$, Ayako Inafune ${ }^{1}$, Tohru Hira ${ }^{1}$, Hirohisa Izumi ${ }^{2}$, Kazuhiro Ozawa ${ }^{2}$, Mitsunori Takase ${ }^{2}$ and \\ Hiroshi HARA ${ }^{1}$ \\ ${ }^{1}$ Division of Applied Bioscience, Research Faculty of Agriculture, Hokkaido University, Sapporo 060-8589, Japan and ${ }^{2}$ Nutritional Sci- \\ ence Laboratory, Morinaga Milk Industry Co. Ltd., Zama 228-8583, Japan
}

(Received 7 May 2009; and accepted 22 May 2009)

\begin{abstract}
We investigated the effects of endogenous glucagon-like peptide-2 (GLP-2) on the development of intestinal mucosa in weanling rats. Three-week-old male weanling Sprague-Dawley rats were administered either anti-GLP-2 or normal rabbit serum every other day for 2 weeks. We then measured length, weight, and bromodeoxyuridine incorporation in the intestine on day 13 following the first injection. Administration of anti-GLP-2 serum significantly inhibited both epithelial proliferation in the distal ileum and elongation of the small intestine. These results suggest that intrinsic GLP-2 contributes to the growth of the small intestine during the weanling period.
\end{abstract}

Glucagon-like peptide-2 (GLP-2) is composed of 33 amino acids and is released in response to luminal nutrient stimuli from enteroendocrine L-cells (4) that reside in the distal part of the intestine (5). GLP-2 promotes epithelial proliferation and protects against intestinal inflammation in animal models $(2$, 8). Such intestinotropic effects have been evaluated mainly via the administration of extrinsic GLP-2 (12) or Gly-Gly-GLP-2, a GLP-2 analogue that is resistant to dipeptidyl peptidase IV (DPP-IV) (1). Transposition of a distal section of the intestine into the proximal area leads to intestinal growth. This indicates that L-cells must be exposed to a greater nutrient supply for intestinal growth to occur (13). Expression of the GLP-2 receptor and concentrations of circulating GLP-2 are enhanced during the neonatal period (9). Furthermore, the response to GLP-2 is temporarily up-regulated after birth (10). In fact, milk protein induces GLP-2 secretion in suckling rats, resulting in subsequent intestinal growth (7). GLP-2 might also play a role in intesti-

Address correspondence to: Dr. Satoshi Ishizuka, Research Faculty of Agriculture, Hokkaido University, Sapporo 060-8589, Japan

Tel: +81-11-706-2811, Fax: +81-11-706-2504

E-mail: zuka@chem.agr.hokudai.ac.jp nal development during the weanling period. In this study, we investigated whether intrinsic GLP-2 is involved in epithelial proliferation. Specifically, we blocked GLP-2 with anti-rat GLP-2 serum for a few weeks after the weanling period.

Weanling male Sprague-Dawley rats (3 weeks old; Japan SLC, Hamamatsu, Japan) weighing 40 to $60 \mathrm{~g}$ were used in this study. The rats were provided free access to water and standard rat chow (CE-2; CLEA Japan, Inc., Tokyo, Japan). Animals were housed in individual cages under controlled temperatures $\left(22 \pm 2^{\circ} \mathrm{C}\right)$ and a $12 \mathrm{~h}$ light:dark cycle. This experiment was approved by the Hokkaido University Animal Use Committee, and animals were maintained according to the university's guidelines for the care and use of laboratory animals.

Antiserum against rat GLP-2 (aGLP-2; Y322, Yanaihara Institute Inc. Fujinomiya, Japan) was used to block endogenous GLP-2, and normal rabbit serum (NRS) was used as a control. Antibody fractions were purified from serum by precipitation with ammonium sulfate and reconstituted in phosphatebuffered saline (PBS). Rats $(\mathrm{n}=12)$ were divided into two groups following 1 day of acclimation. Each group of rats was injected subcutaneously with either NRS or aGLP-2 (1 mg/g body weight) every other day. On day 13 after the first injection, rats 
were decapitated under diethylether anesthesia. Each rat received a subcutaneous dose of bromodeoxyuridine $(\mathrm{BrdU})$ solution $1 \mathrm{~h}$ before sacrifice, as previously reported (7). The entire small intestine, cecum, and colorectum were removed and flushed with saline. The weight and length of the small intestine and colorectum were then measured. The small intestine was divided by length into four equal parts (duodenum, jejunum, proximal ileum, and distal ileum) that were fixed in $10 \%$ formalin in PBS for immunohistochemistry.

Frozen sections of intestinal segments were treated with $10 \%$ NRS in PBS to block non-specific binding. We used mouse anti-BrdU antibodies (Clone NA-20; Calbiochem, EMD Chemicals, Inc., Darmstadt, Germany) and biotinylated rabbit anti-mouse $\operatorname{IgG}+\mathrm{A}+\mathrm{M}(\mathrm{H}+\mathrm{L})$ as the primary and secondary antibodies, respectively. We scored the epithelial cells from the bottom of the crypt to cell position 20 within a crypt under a microscope, as described previously (7). Fifty well-organized crypt sections were scored in each site of the intestine. Epithelial proliferation was evaluated as a ratio of the number of BrdU-incorporating epithelial cells to the total number of cells in the epithelial layer of the crypts.

Statistical differences between groups were assessed using a Student's $t$-test and Hsu's MCB test with JMP software (SAS institute, Cary, NC). A two-way analysis of variance was performed for quantitative data from BrdU staining (treatment $x$ site). A $P$-value of less than 0.05 was considered statistically significant.

To investigate whether intrinsic GLP-2 influences early intestinal development in weanling rats, we blocked endogenous GLP-2 by administering aGLP-2 for approximately 2 weeks. We found that the small intestine was significantly shorter in aGLP-2-treated rats than in NRS-treated controls. A similar trend was observed in the colon; however, no significant difference was observed between treatments $(\mathrm{Ta}-$ ble 1). BrdU histochemistry revealed that aGLP-2 administration significantly reduced the proportion of BrdU-incorporating crypt epithelial cells in the distal ileum (Fig. 1). A two-way analysis of variance showed that aGLP-2 treatment significantly inhibited BrdU incorporation in the small intestine $(P=0.0379$ for treatment). We did not measure BrdU incorporation in the cecum and colorectum because no significant differences were observed in either the length or weight of these sites. Body weight gain and small intestine, cecum, and colorectum weights tended to be low in aGLP-2-treated rats; however, no statistically significant difference was
Table 1 Growth and organ parameters of growing rats administered aGLP-2 or normal rabbit serum (NRS)

\begin{tabular}{lrc}
\hline & \multicolumn{1}{c}{ NRS } & \multicolumn{1}{c}{ aGLP-2 } \\
\hline Body weight gain $(\mathrm{g})$ & $117.7 \pm 3.5$ & $109.9 \pm 7.4$ \\
Organ weight $(\mathrm{g})$ & & \\
$\quad$ Small intestine & $6.87 \pm 0.23$ & $6.37 \pm 0.40$ \\
Cecum & $1.00 \pm 0.03$ & $0.92 \pm 0.07$ \\
$\quad$ Colorectum & $1.36 \pm 0.06$ & $1.14 \pm 0.11$ \\
Organ length (cm) & & \\
$\quad$ Small intestine & $97.1 \pm 1.9$ & $91.2 \pm 1.7^{*}$ \\
Colorectum & $16.4 \pm 0.5$ & $15.5 \pm 0.5$ \\
\hline
\end{tabular}

Values are mean $\pm \operatorname{SEM}(n=6)$.

*Significantly different from the values of the NRS-treated group $(P<0.05)$.

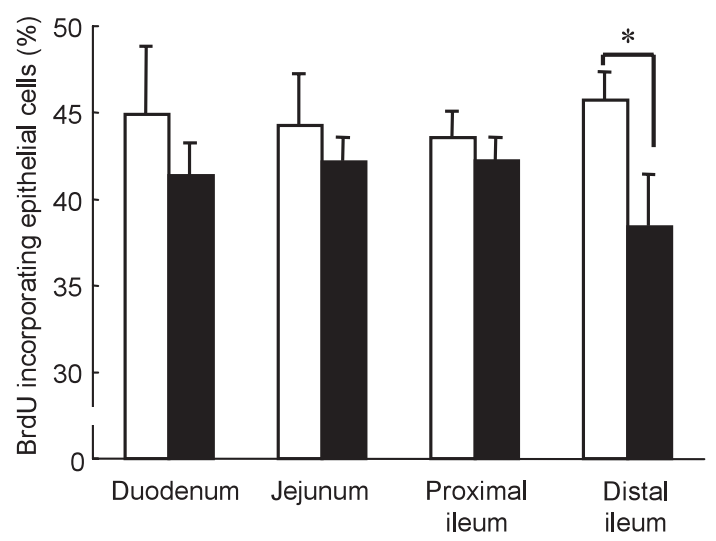

Fig. 1 BrdU incorporation of epithelial cells in the small intestine of weanling rats administered either aGLP-2 (solid bars) or normal rabbit serum (open bars) for 13 days. Values are mean and SEM. *Statistically significant difference between groups $(P<0.05, \mathrm{n}=6)$.

detected (Table 1).

Several reports using mature, adult animals have verified the intestinotropic effects of GLP-2 $(1,4)$. In this experiment, we sought to clarify the intrinsic effects of GLP-2 on the development of the intestinal epithelia in weanling rats. We found that administration of aGLP-2 suppressed BrdU incorporation in the epithelial cells and inhibited elongation of the small intestine in weanling rats. Exposure of L-cells to nutrient-rich chyme is important for intestinal growth (13). The growth rate of intestinal tissue is much higher during the suckling period than the post-weanling period (11). Previously, we found that GLP-2 was involved in intestinal growth during the suckling period in response to milk protein (7). The results of the present study also support the hypothesis that intrinsic GLP-2 contributes to intestinal growth during the weanling period, just after the 
suckling period. During growth in the suckling and weanling period, the gastrointestinal tract, especially the small intestine, develops extensively. In contrast, there is almost no need for intestinal growth in adults. Endogenous GLP-2 plays a substantial role in intestinal development during both the suckling and weanling periods.

GLP-2 is thought to act in an endocrine manner. However, DPP-IV inactivates GLP-2 soon after release, and the clearance of GLP-2 is quite rapid (3). The plasma half-life of GLP-2 in the active form is estimated at approximately $7 \mathrm{~min}$. Studies in pigs have shown that the metabolite of GLP-2 (3-33) is eliminated with a half-life of $22 \mathrm{~min}$ (6). In this study, inhibitory effects of aGLP-2 were observed at the distal ileum, where L-cells are densely localized (5). GLP-2 might remain at a relatively higher concentration in the distal small intestine than the proximal intestine because of the rapid inactivation of GLP-2. Our results suggest that endogenous GLP-2 preferentially acts in the distal section of the intestine in a paracrine manner during the weanling period. Thus, the effects of intrinsic GLP-2 on intestinal growth are probably limited to the distal ileum.

In conclusion, intrinsic GLP-2 promotes epithelial proliferation in the distal small intestine during the weanling period, thus indicating its contribution to the growth of the small intestine.

\section{REFERENCES}

1. Booth C, Booth D, Williamson S, Demchyshyn LL and Potten CS (2004) Teduglutide ([Gly2]GLP-2) protects small intestinal stem cells from radiation damage. Cell Prolif 37, 385-400.

2. Boushey RP, Yusta B and Drucker DJ (1999) Glucagon-like peptide 2 decreases mortality and reduces the severity of indomethacin-induced murine enteritis. Am J Physiol 277,
E937-E947.

3. Drucker DJ, Shi Q, Crivici A, Sumner-Smith M, Tavares W, Hill M, DeForest L, Cooper S and Brubaker PL (1997) Regulation of the biological activity of glucagon-like peptide 2 in vivo by dipeptidyl peptidase IV. Nat Biotechnol 15, 673677.

4. Drucker DJ (2003) Glucagon-like peptides: regulators of cell proliferation, differentiation, and apoptosis. Mol Endoclinol 17, 161-171.

5. Eissele R, Göke R, Willemer S, Harthus HP, Vermeer H, Arnold R and Göke B (1992) Glucagon-like peptide-1 cells in the gastrointestinal tract and pancreas of rat, pig and man. Eur J Clin Invest 22, 283-291.

6. Hansen L, Hare KJ, Hartmann B, Deacon CF, Ugleholdt RK, Plamboeck A and Holst JJ (2007) Metabolism of glucagonlike peptide-2 in pigs: role of dipeptidyl peptidase IV. Regul Pept 138, 126-132.

7. Izumi H, Ishizuka S, Inafune A, Hira T, Ozawa K, Shimizu T, Takase M and Hara H (2009) a-Lactalbumin hydrolysate stimulates glucagon-like peptide-2 secretion and small intestinal growth in suckling rats. J Nutr 139, 1322-1327.

8. L'Heureux MC and Brubaker PL (2003) Glucagon-like peptide- 2 and common therapeutics in a murine model of ulcerative colitis. $J$ Pharmacol Exp Ther 306, 347-354.

9. Lovshin J, Yusta B, Iliopoulos I, Migirdicyan A, Dableh L, Brubaker PL and Drucker DJ (2000) Ontogeny of the glucagon-like peptide-2 receptor axis in the developing rat intestine. Endocrinology 141, 4194-4201.

10. Petersen YM, Burrin DG and Sangild PT (2001) GLP-2 has differential effects on small intestine growth and function in fetal and neonatal pigs. Am J Physiol 281, R1986-R1993.

11. Sakata T and Setoyama H (1997) Bi-phasic allometric growth of the small intestine, cecum and the proximal, middle, and distal colon of rats (Rattus norvegicus Berkenhout, 1764) before and after weaning. Comp Biochem Physiol A Physiol 118, 897-902.

12. Shin ED, Estall JL, Izzo A, Drucker DJ and Brubaker PL (2005) Mucosal adaptation to enteral nutrients is dependent on the physiologic actions of glucagon-like peptide- 2 in mice. Gastoloenterology 128, 1340-1353.

13. Thulesen J, Hartmann B, Kissow H, Jeppesen PB, Orskov C, Holst JJ and Poulsen SS (2001) Intestinal growth adaptation and glucagon-like peptide 2 in rats with ileal-jejunal transposition or small bowel resection. Dig Dis Sci 46, 379-388. 